\title{
ERRATA
}

\section{SLIDING-VIBRATING RESPONSE OF ELASTIC STRUCTURES}

by Fu Yu-An

Vol. 21, no. 3, september 1988, pp190-197.

Location

P.191, line 3

P.191, Formula (6)

P.191-192, Fig.2 - 4

P.192, Eormula (10)

P.192, Formula (15)

P.193, Formula (21)

P.193, Formula (23)

P.193, Formula (24)

P.193, Formula (28)

$$
\text { top mass } M_{2}
$$$$
\mid u(t)
$$

gu

$\mathrm{Y}+\ldots$

$\pi^{3}$

$\mathrm{N}$

$\ddot{\delta}_{1}$

$\ddot{\delta}_{2}$

$\delta(t)=\frac{1}{\sqrt{1-\frac{M_{1}+M_{2}}{M_{2}} \xi^{2}} \sqrt{\frac{M_{1}+M_{2}}{M_{2}} \rho}} \int^{t} \cdots$

$\cos \epsilon=\sqrt{1-\frac{M_{1}+M_{2}}{M_{2}}} 2$

$\sin t=\sqrt{\frac{M_{1}+M_{2}}{M_{2}}}$

$\frac{\mathrm{P}(\mathrm{Hz})}{2 \mathrm{x}_{2}{ }^{7}}$

702

$\ldots$ in a $\ldots$

$\mathrm{T}_{\mathrm{O}}=0$

$P=5 * 2$

\section{Correction}

base mass $M_{2}$

$|\ddot{u}(t)|$

$\mathrm{g} \mu$

$\ddot{\mathrm{Y}}+\ldots$

$\pi^{2}$

M

$\ddot{u}_{1}$

$\ddot{u}_{2}$

$\delta(t)=\frac{-1}{\sqrt{1-\frac{M_{1}+M_{2}}{M_{2}} \xi^{2} \sqrt{\frac{M_{1}+M_{2}}{M_{2}}} \rho}} \int_{0}^{t} .$.

$\cos \epsilon=\sqrt{1-\frac{M_{1}+M_{2}}{M_{2}} \xi^{2}}$

$\sin \epsilon=\sqrt{\frac{{ }_{1}+M_{2}}{M_{2}} \xi}$

$\frac{P(r / s)}{2 \pi .7}$

402

$\ldots$ and a ...

$\mathrm{T}_{\mathrm{O}}=0.184$

$P=5 * 2 \pi$ 
EARTHQUAKE DAMAGE AT EDGECUMBE AND KAWARAU

ELECTRICORP SUBSTATIONS IN THE BAY OF PLENTY EARTHQUAKE ON 2 MARCH 1987

by A.L. Rutledge

Vol. 21, no. 4, December 1988, pp247-254.

Unfortunately, a large number of typographical errors crept in to this article while preparing it for publication. This is regretted. The corrections are (hopefully) obvious in most cases but some may not be and these are given below.

In the title and elsewhere:

"Kawarau" should read "Kawerau".

P. 247, col. 1, line 21:

"proponion" should read "proportion".

P. 247, col. 2, line 3:

"Mdatahina" should read "Matahina".

P. 250, col. 2, 32 lines from the bottom:

"8g7" should read "87".

P. 250, col. 2, 8 lines from the bottom:

"Kaweruu" should read "Kawerau"

"Feranti" should read "Ferranti". 